\title{
Insights into the Structure-Reactivity of Supported Au Nanocatalyst during Butadiene Selective Hydrogenation by Atomic Scale In Situ Environmental TEM
}

\author{
$\underline{\text { Abdallah Nassereddine }}^{1}$, Christian Ricolleau ${ }^{1}$, Damien Alloyeau ${ }^{1}$, Guillaume Wang ${ }^{1}$, Catherine Louis ${ }^{2}$, \\ Laurent Delannoy $^{2}$, and Jaysen Nelayah ${ }^{1}$ \\ ${ }^{1}$ Laboratoire Matériaux et Phénomènes Quantiques, Université de Paris, CNRS, F-75013, Paris. \\ ${ }^{2}$ Laboratoire de Réactivité de Surface, Sorbonne Université, CNRS, F-75005, Paris.
}

Although bulk gold is chemically inert, gold catalysts containing small gold nanoparticles (NPs $<10 \mathrm{~nm}$ ) are known to be reactive in various oxidation and hydrogenation reactions [1]. In particular, oxidesupported Au has been identified since 1973 as an active catalyst in alkene hydrogenation and selective hydrogenation of diolefins like 1,3 butadiene [2] [3]. In this reaction, it was generally admitted that the rate determining step is the dissociative adsorption of $\mathrm{H}_{2}$ molecules on the catalyst surface. Several experimental and theoretical studies have hinted that the activity of Au catalysts is generally attributed to the dissociation of $\mathrm{H}_{2}$ molecules on the low coordinated neutral $\mathrm{Au}$ atoms (corner and edge positions) with little or no change of particle structure and morphology during reaction [4]. This paradigmatic picture of $\mathrm{Au}$ catalysts is still under debate due to the lack of direct observation of gold nanoparticles in the reaction environment. In this contribution, we present a new atomic scale insight into the structural dynamics of a small $(\sim 5 \mathrm{~nm})$ and ultrasmall $(\sim 3 \mathrm{~nm})$ Au NPs under $\mathrm{H}_{2}$ at atmospheric pressure and in hydrogenation of butadiene $\left(\mathrm{C}_{4} \mathrm{H}_{6}\right)$ using environmental TEM (ETEM).

The studied $\mathrm{Au}$ NPs were synthesized by deposition-precipitation with urea on anatase $\mathrm{TiO}_{2}$ support [5]. ETEM experiments were performed on a double aberration-corrected JEOL ARM 200 F microscope using a Protochips Atmosphere ${ }^{\mathrm{TM}}$ TEM environmental high-pressure gas cell. The structural evolution of small $(\sim 5 \mathrm{~nm})$ and ultrasmall $(\sim 3 \mathrm{~nm})$ Au NPs was studied during the exposure to static (i) $\mathrm{H}_{2}$ pure gas (ii) $\mathrm{C}_{4} \mathrm{H}_{6} / \mathrm{He}$ gas mixtures and (iii) $\mathrm{H}_{2} / \mathrm{C}_{4} \mathrm{H}_{6} / \mathrm{He}$ gas mixtures at atmospheric pressure and temperatures up to $400{ }^{\circ} \mathrm{C}$. Figure 1 and Figure 2 show in situ HAADF-STEM imaging of the atomic structure and morphology of FCC Au NPs under $10^{5} \mathrm{~Pa}$ of $\mathrm{H}_{2}$ and $\mathrm{C}_{4} \mathrm{H}_{6} / \mathrm{He}$ respectively. Under $10^{5} \mathrm{~Pa}$ of $\mathrm{H}_{2}$, sizedependent reactivity of $\mathrm{Au}$ NPs is revealed. While small $\mathrm{Au}$ NPs $(\sim 5 \mathrm{~nm})$ remain rigid and maintain their initial FCC structure during cooling from 400 to $25^{\circ} \mathrm{C}$, ultrasmall $\mathrm{Au}$ NPs $(\sim 3 \mathrm{~nm})$ exhibit structural fluctuations from FCC to non FCC structures (icosahedral symmetries, disordered multi-domain structures) at temperature as high as $400{ }^{\circ} \mathrm{C}$. In contrast, in situ HAADF-STEM observations of small Au NPs $(\sim 5 \mathrm{~nm})$ under $10^{5} \mathrm{~Pa}$ of $\mathrm{C}_{4} \mathrm{H}_{6}$ shows instantaneous changes in the shape of Au NPs at $300{ }^{\circ} \mathrm{C}$, while maintaining its initial FCC structures. These observations will be discussed in conjunction with the catalytic performances results of these Au NPs in the selective hydrogenation of butadiene reaction during laboratory catalytic test. 


\section{References:}

[1] A Hashmi et al, Angew. Chem. Int. Ed. 45 (2006), p. 7896.

[2] GC Bond et al, J. Chem. Soc. Chem. Commun. 13 (1973), p. 444b.

[3] PA Sermon et al, J. Chem. Soc. Faraday Trans. 75 (1979), p. 385.

[4] GC Bond et al, Gold Bulletin 49 (2016), p. 53.

[5] Delannoy et al, Phys. Chem. Chem. Phys. 48 (2014), p. 26514.

[6] This work was supported by the French National Research Agency through the TOTEM project,

Grant Number ANR-17- CE07-0031.
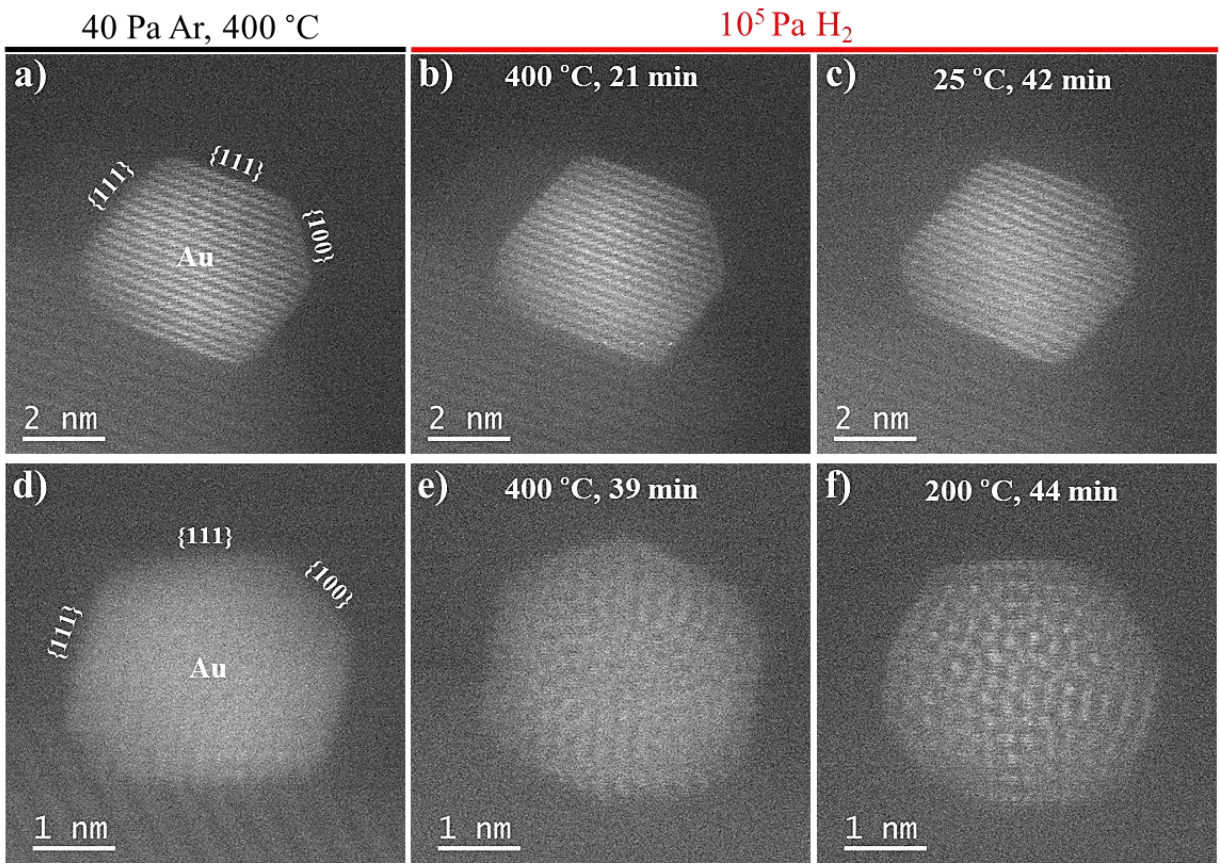

Figure 1. In situ STEM observation of the structure of a small $\mathrm{Au} \mathrm{NP}$ of $4.5 \mathrm{~nm}$ (high row) and an ultrasmall $\mathrm{Au} \mathrm{NP}$ of $3.5 \mathrm{~nm}$ (low row) in $\mathrm{Au} / \mathrm{TiO}_{2}$ catalyst. (a,d) under $40 \mathrm{~Pa}$ of $\mathrm{Ar}$ at $400{ }^{\circ} \mathrm{C}$, (b,e) under $10^{5} \mathrm{~Pa}$ of $\mathrm{H}_{2}$ at $400{ }^{\circ} \mathrm{C}$, (c,f) after to $25^{\circ} \mathrm{C}$.

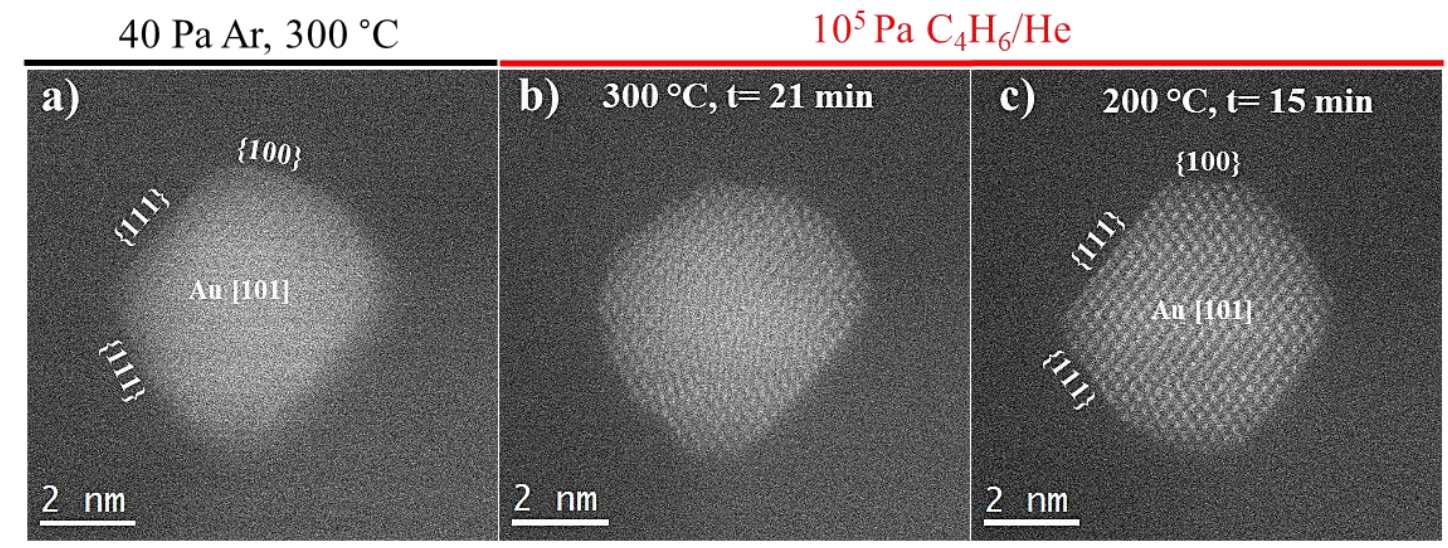

Figure 2. In situ STEM observation of the structure of a small $\mathrm{Au} \mathrm{NP}$ of $5 \mathrm{~nm}$ in $\mathrm{Au} / \mathrm{TiO}{ }_{2}$ catalyst. (a) under $40 \mathrm{~Pa}$ of $\mathrm{Ar}$ at $300{ }^{\circ} \mathrm{C}$, (b,c) under $10^{5} \mathrm{~Pa}$ of $\mathrm{C}_{4} \mathrm{H}_{6}$ at $300{ }^{\circ} \mathrm{C}$ and $200{ }^{\circ} \mathrm{C}$. 